\title{
PENERAPAN MODEL PEMBELAJARAN PICTURE AND PICTURE PADA MATERI PRINSIP KERJA SISTEM PENGAPIAN ELEKTRONIK
}

\author{
Elisnawati ${ }^{1}$, Debora ${ }^{2}$, Jhonni Rentas Duling ${ }^{3}$ \\ ${ }^{1,2,3}$ Fakultas Keguruan Ilmu Pendidkan, Universitas Palangka Raya \\ Email: elisnawati42@yahoo.com
}

\begin{abstract}
From the results of observations and interviews with the teacher who taught the material understand the working principle of an electronic ignition system at SMK Negeri 2 Katingan Hilir, it's known that the value of TBSM class XI students has not been fully achieved. This is related to the learning outcomes of some students who scored below 65, which did not meet the KKM score set by the school. This study aims to find out how student learning outcomes after applying the picture and picture learning model. The collection is done by using test methods in the form of pre-test and post-test, student response questionnaire, observation in the form of teacher activity sheets and student activity sheets, as well as documentation. The application of the picture and picture learning model to the material understanding the working principle of electronic ignition system of the students of Vocational High School 2 Katingan Hilir, which has been able to make students who take this model successfully obtain complete results and exceed the KKM set by the school which is 70 with 85.67 and lowest value 69 and classical completeness $95.83 \%$. There is a significant increase in student learning outcomes.
\end{abstract}

Keywords: Learning Outcomes, Electronic Ignition System

\section{PENDAHULUAN}

Undang-Undang Nomor 20 Tahun 2003 memuat tentang fungsi Pendidikan Nasional mengembangkan kemampuan dan membentuk watak serta peradaban bangsa yang bermartabat dalam rangka mencerdaskan kehidupan bangsa, bertujuan untuk berkembangnya potensi peserta didik agar menjadi manusia yang beriman dan bertakwa kepada Tuhan Yang Maha Esa, berakhlak mulia, sehat, berilmu, cakap, kreatif, mandiri, dan menjadi warga Negara yang demokratis serta bertanggung jawab. Di dalam Undang-Undang juga termuat tentang Sistem Pendidikan Nasional menyatakan bahwa pendidikan adalah usaha sadar dan terencana untuk mewujudkan suasana belajar dan proses pembelajaran agar peserta didik secara aktif mengembangkan potensi dirinya untuk memiliki kekuatan spritual keagamaan, pengendalian diri, kepribadian, kecerdasan, akhlak mulia, serta keterampilan yang diperlukan dirinya, masyarakat, bangsa dan negara.

Berdasarkan hasil pengamatan yang dilakukan oleh peneliti di kelas XI Teknik Bisnis Sepeda Motor (TBSM) SMKN 2 Katingan Hilir, peneliti menemukan suatu fenomena dimana dalam proses pembelajaran pemeliharaan listrik sepeda motor guru lebih banyak menggunakan metode konvensional dalam menyampaikan materi prinsip kerja sistem pengapian elektronik di kelas. Siswa cenderung sulit mengerti penjelasan yang sudah disampaikan oleh guru dan siswa juga tidak mau bertanya serta tidak berani untuk mengungkapakan pendapatnya, meskipun guru memberikan kesempatan kepada siswa, hal ini juga yang membuat pembelajaran hanya terpusat kepada guru. Kegiatan pembelajaran yang didominasi oleh guru menyebabkan siswa masih pasif. Siswa hanya mendengarkan penjelasan guru, sehingga proses belajar mengajar cenderung membosankan dan membuat siswa kurang termotivasi dalam mengikuti pembelajaran.

Berdasarkan hasil observasi dan wawancara dengan guru yang mengajar mata pelajaran pemeliharaan listrik sepeda motor pada materi prinsip kerja sistem pengapian elektronik di kelas XI TBSM SMK Negeri 2 Katingan Hilir diketahui nilai akhir siswa belum tercapai sepenuhnya. Hasil belajar siswa yang mendapat nilai masih di bawah 65 dan untuk tingkat ketuntasan siswa pada Tahun Ajaran 2017/2018 yang mencapai KKM hanya 42,85\% dan 57,14\% tidak mencapai KKM. Hal ini menunjukkan bahwa nilai yang didapatkan siswa belum semuanya mencapai nilai standar KKM yang ditetapkan oleh sekolah yaitu 70. Belum tercapainya nilai KKM siswa pada materi prinsip kerja pengapian elektronik disebabkan oleh beberapa faktor yaitu faktor guru dan faktor siswa tersebut. 
Faktor-faktor yang menyebabkan rendahnya nilai siswa adalah sebagai berikut: (1) proses pembelajaran masih konvensional; (2) siswa kurang aktif selama proses pembelajaran; (3) siswa kurang memahami kosep saat pembelajaran berlangsung; dan (4) keterbatasan sarana dan prasarana yang dimiliki sekolah mempengaruhi proses dalam belajar mengajar.

Metode pembelajaran yang digunakan guru tidak salah, namun dengan metode ceramah interaksi guru dan siswa tidak berjalan dengan baik. Metode ceramah juga tidak dapat dilepaskan dari proses pembelajaran, hanya saja perlu adanya variasi pembelajaran yang dikemas dengan lebih baik dan menarik. Guru tidak hanya dituntut sekedar menyampaikan ilmu, tetapi harus dapat pula menciptakan suasana pembelajan yang kondusif sehingga proses pembelajaran dapat berlangsung secara aktif dan tujuan pembelajaran dapat tercapai dengan baik.

Hal ini menyebabkan peneliti memilih menerapkan model pembelajaran yang bisa digunakan oleh guru guna meningkatkan keaktifan siswa adalah mengunakan model pembelajran picture and picture. Model pembelajaran picture and picture adalah model pembelajaran yang menggunakan gambar dan pasangkan atau diurutkan menjadi urutan logis. Model pembelajaran ini mengandalkan gambar yang menjadi faktor utama dalam proses pembelajaran. Maka dari itu, sebelumnya guru sudah menyiapkan gambar yang akan ditampilkan. Gambar sangat penting digunakan untuk memperjelas pengertian. Melalui gambar, siswa mengetahui hal-hal yang belum pernah dilihatnya. Gambar dapat membantu guru mencapai tujuan intruksional karena selain merupakan media yang murah dan mudah diperoleh, juga dapat meningkatkan keaktifan siswa. Selain itu, pengetahuan dan pemahaman siswa menjadi lebih luas, jelas, dan tidak mudah dilupakan Shoimin (2013:122).

Model pembelajaran picture and picture (mengurutkan gambar) sangat cocok untuk materi prinsip kerja sistem pengapian elektronik, karena harus mengurutkan gambar cara kerja sistem pengapian elektronik, siswa mengurutkan gambar komponen sistem pengapian elektronik, siswa mengurutkan gambar cara pemeriksaan dan perbaikan sistem pengapian elektronik.

Dengan menggunakan model pembelajaran ini diharapkan dapat meningkatkan hasil belajar siswa. Berdasarkan pernyataan-pernyataan di atas maka perlu dilakukannya penelitian dengan judul "penerapan model pembelajaran picture and picture pada materi prinsip kerja sistem pengapian elektronik"

\section{METODE}

Penelitian ini menggunakan pendekatan kuantitatif. Populasi dalam penelitian ini adalah siswa kelas XI TBSM SMK Negeri 2 Katingan Hilir tahun ajaran 2018/2019 berjumlah 26 orang. Dalam penelitian ini peneliti mengambil kelas XI TSM dengan jumlah sebanyak 24 orang siswa sebagai sampel. Sampel yang terpilih diberi pretes, bertujuan untuk mengetahui pengetahuan serta pemahaman peserta didik terhadap materi prinsip kerja sistem pengapian elektronik dan merawat berkala sistem pengapian elektronik. Sampel diberi perlakuan menggunakan model picture and picture dan diberi posttes untuk mengetahui peningkatan nilai hasil belajar. Data dianalisis dengan menggunakan statistik deskriptif, berupa persentase, dan grafik.

\section{HASIL DAN DISKUSI}

Data yang disajikan merupakan data dari hasil tes belajar siswa kelas XI TBSM dari 24 jumlah siswa. Data tersebut di peroleh data dari posttest. Hasil test dilakukan untuk mengetahui ada tidaknya peningkatan hasil belajar siswa setelah dilakukan perlakuan pada kelas XI TBSM SMK Negeri 2 Katingan Hilir. Setelah dilakukan perlakuan, dapat dilihat perbedaan antara nilai tes yang signifikan. Data hasil tes selengkapnya dapat dilihat pada Gambar 1.

Berdasarkan Gambar 1 dapat diketahui bahwa nilai siswa mengalami peningkatan pada materi prinsip kerja sistem pengapian elektronik di mana 23 siswa tuntas dari 24 siswa, telah mencapai atau melebihi KKM yang di terapkan di sekolah yaitu 70, setelah dilakukan model pembelajaran picture and picture. Dengan demikian, ketuntasan hasil belajar siswa dapat meningkat dengan menggunakan model pembelajaran picture and picture. Untuk tingkat penguasaan hasil belajar materi merawat secara berkala mekanisme katup setelah menerapkan model pembelajaran picture and picture yaitu : $\mathrm{N}_{\text {klasikal }}=95,83 \%$. 


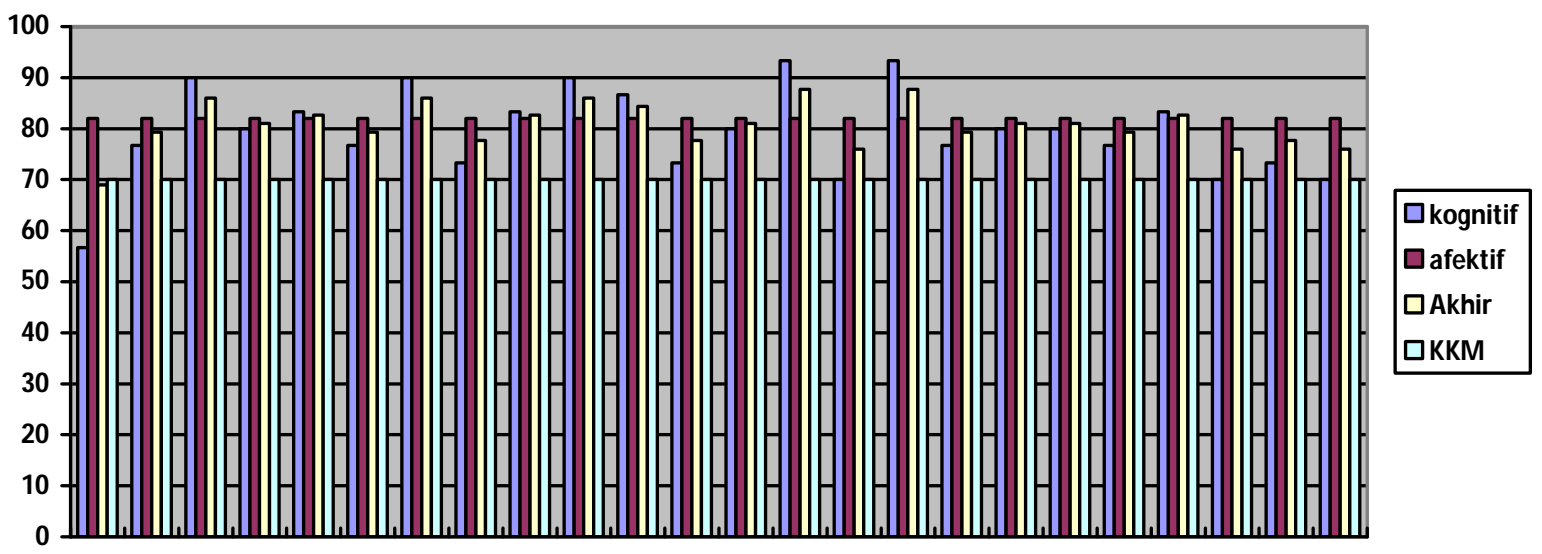

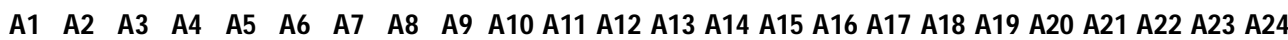

Gambar 1. Nilai Akhir Siswa

Ketika proses pembelajaran pada materi prinsip kerja sistem pengapian elektronik berlangsung, aktivitas guru diamati. Berdasarkan hasil angket, dapat disimpulkan bahwa kegiatan belajar dalam model pembelajaran picture and picture berjalan dan terlaksana dengan baik.

Berdasarkan analisis pada lembar aktivitas guru dalam kegiatan pembelajaran menunjukkan bahwa penerapan model pembelajaran picture and picture dapat meningkatkan keaktifan dan rasa ingin tahu siswa dalam proses pembelajaran. Ini menunjukkan bahwa aktivitas guru sangat efektif dalam penerapan model pembelajaran picture and picture. Hasil pengamatan aktivitas siswa selama kegiatan pembelajaran dengan model pembelajaran picture and picture disajikan pada Gambar 2.

Kegiatan siswa pada proses pembelajaran materi sistem pengapian elektronik dengan model pembelajaran picture and picture umumnya berjalan dengan baik. Berdasarkan hasil pengamatan, aktivitas siswa menjadi lebih hidup, misalnya: memperhatikan materi pelajaran, berusaha melakukan pembelajaran dengan baik, menanyakan hal-hal yang belum jelas pada guru, berusaha menyimpulkan materi yang telah dipelajari, dan menjawab soal yang telah diberikan. Aktivitas siswa sangat dominan dalam pembelajaran, siswa sangat tertarik ketika guru menunjukan gambar-gambar yang harus mereka susun menjadi urutan yang benar, siswa sangat aktif mencari tahu saat pembelajaran berlangsung, terlihat ketika guru menyampaikan materi memahami prinsip kerja sistem pengapian elektronik. Pada tahap ini tujuan pembelajaran yang ingin dicapai dapat disampaikan secara efektif kepada siswa.

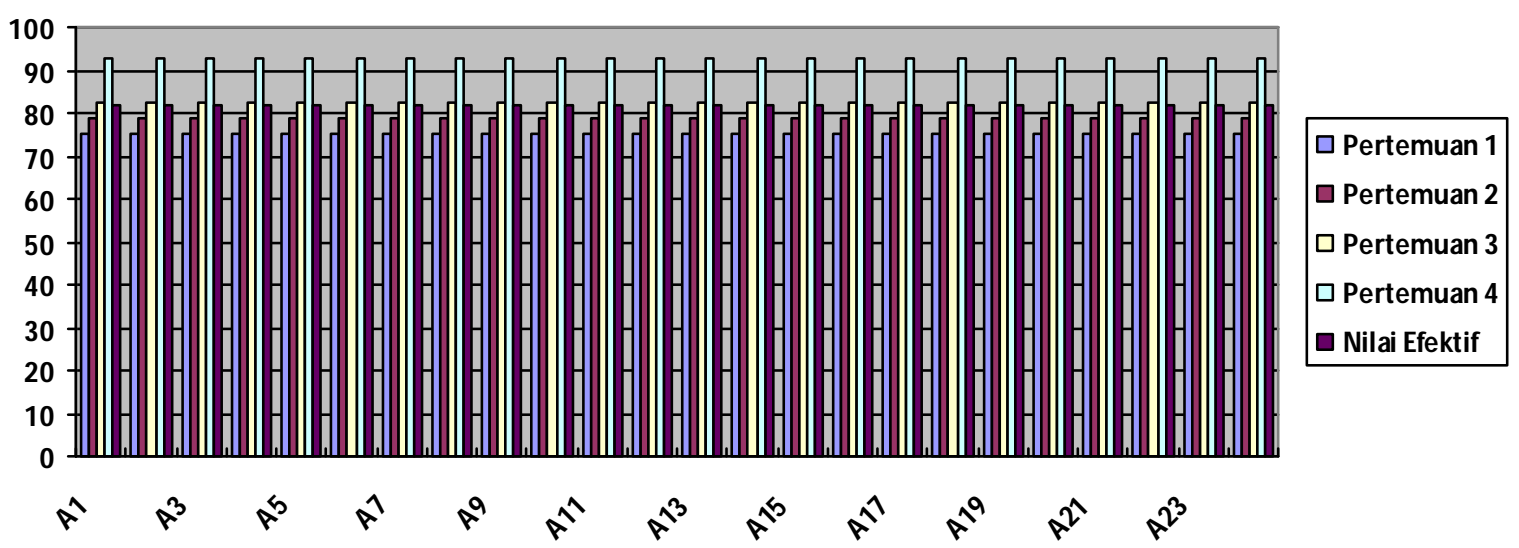

Gambar 2. Skor Keaktifan Siswa 
Berdasarkan pembahasan yang telah diuraikan, dapat disimpulkan bahwa semua aktivitas yang telah dilakukan oleh siswa mencerminkan bahwa penerapan model pembelajaran picture and picture dalam pembelajaran dapat membuat siswa lebih aktif dalam berinteraksi dengan teman dan guru. Ini menandakan aktivitas siswa baik dalam penerapan model pembelajaran picture and picture mata pelajaran pemeliharaan kelistrikan sepeda motor pada pada materi memahami prinsip kerja sistem pengapian elektronik kelas XI TBSM SMK Negeri 2 Katingan Hilir.

Tabel 1. Persentase Angket Respon Siswa

\begin{tabular}{|c|c|c|c|c|}
\hline \multirow{2}{*}{ No. } & \multirow{2}{*}{ Pernyataan } & \multicolumn{3}{|c|}{ Respon Siswa } \\
\hline & & SS & S $\quad$ TS & STS \\
\hline 1 & $\begin{array}{l}\text { Pembelajaran sistem pengapian elektronik dengan } \\
\text { menggunakan model pembelajaran picture and picture }\end{array}$ & $75 \%$ & $25 \%$ & \\
\hline 2 & $\begin{array}{l}\text { Menjadi lebih mudah memahami pembelajaran dengan } \\
\text { menggunakan model pembelajaran picture and picture }\end{array}$ & $83,3 \%$ & $16,7 \%$ & \\
\hline 3 & $\begin{array}{l}\text { Dengan model pembelajaran picture and picture, menjadi } \\
\text { lebih cepat tanggap karena menggunkan media gambar }\end{array}$ & $70,8 \%$ & 29,2 & \\
\hline 4 & $\begin{array}{l}\text { Lebih mudah berkonstrasi dalam belajar dengan } \\
\text { menggunakan model picture and picture }\end{array}$ & $95,8 \%$ & $4,2 \%$ & \\
\hline 5 & $\begin{array}{l}\text { Dengan menggunakan model pembelajaran picture and } \\
\text { picture membuat anda menjadi lebih mudah mengingat } \\
\text { konsep pembelajaran }\end{array}$ & $79,2 \%$ & $20,8 \%$ & \\
\hline 6 & $\begin{array}{l}\text { Dengan model pembelajaran picture and picture pada sistem } \\
\text { pengapian elektronik menarik karena menggunakan media } \\
\text { gambar }\end{array}$ & $66,7 \%$ & $33,3 \%$ & \\
\hline 7 & $\begin{array}{l}\text { Dengan menggunakan model pembelajaran picture and } \\
\text { picture, menjadi lebih aktif }\end{array}$ & $79,2 \%$ & 20,8 & \\
\hline 8 & $\begin{array}{l}\text { Dengan menggunakan model pembelajaran picture and } \\
\text { picture pada matrei prinsip kerja sistem pengapian } \\
\text { elektronik menjadi lebih bermanfaat untuk anda }\end{array}$ & $87,5 \%$ & 12,5 & \\
\hline 9 & $\begin{array}{l}\text { Dengan model pembelajaran picture and picture membuat } \\
\text { anda lebih berani mengungkapkan ide/pendapat dan } \\
\text { bertanya jika ada yang belum dipahami }\end{array}$ & $75 \%$ & $25 \%$ & \\
\hline
\end{tabular}

Keterangan :

SS = Sangat Setuju, $\mathrm{S}=$ Setuju, TS = Tidak Setuju, STS $=$ Sangat Tidak Setuju

Berdasarkan Tabel 1, diperoleh tanggapan $75 \%$ sangat setuju dan $25 \%$ setuju bahwa penerapan model pembelajaran picture and picture pada materi sistem pengapian elektronik; 83,3\% sangat setuju dan $16,7 \%$ setuju bahwa siswa merasa lebih mudah memahami sistem pengapian elektronik dengan menggunakan model pembelajaran picture and picture; 70,8\% sangat setuju dan $29,2 \%$ setuju bahwa siswa merasa lebih cepat tanggap terhadap sistem pengapian elektronik menggunakan model pembelajaran picture and picture; $95,8 \%$ sangat setuju dan 4,2\% setuju bahwa siswa merasa menjadi lebih mudah berkonsentrasi pembelajaran menggunakan model pembelajaran picture and picture; $79,2 \%$ sangat setuju dan $20,8 \%$ setuju bahwa siswa merasa lebih mudah mengingat konsep pembelajaran menggunakan model pembelajaran picture and picture; $66,7 \%$ sangat setuju dan $33,3 \%$ setuju bahwa siswa merasa pembelajaran lebih menarik setelah menggunakan model pembelajaran picture and picture; $79,2 \%$ sangat setuju dan 20,8\% setuju bahwa siswa aktif setelah melakukan pembelajaran dengan menggunakan model pembelajaran picture and picture; $87,5 \%$ sangat setuju dan $12,5 \%$ setuju bahwa siswa merasa pembelajaran sistem pengapian elektronik lebih bermanfaat menggunakan model pembelajaran picture and picture; $75 \%$ sangat setuju dan $25 \%$ setuju bahwa siswa merasa bahwa dengan model pembelajaran picture and picture mereka menjadi lebih berani mengungkapakan pendapat dan bertanya jika ada hal yang tidak dipahami.

\section{SIMPULAN}

Berdasarkan hasil penelitian disimpulkan bahwa dengan menerapkan model pembelajaran picture and picture siswa menjadi lebih mudah memahami konsep pembelajaran. Hal ini menunjukkan 
bahwa dalam proses pembelajaran dengan menggunakan model picture and picture membuat siswa lebih fokus, termotivasi dalam pembelajaran, berani mengungkapkan pendapat serta mampu bertanggung jawab dalam pelajaran. Dengan demikian, model pembelajaran picture and picture dapat dijadikan sebagai alternatif model pembelajaran.

\section{DAFTAR RUJUKAN}

Peraturan Pemerintah. (2010). Diunduh pada tanggal 7 Agustus 2018, dari http://www.google.com. peraturanpemerintah.com.

Shoimin, Aris. (2014). 68 Model Pembelajaran Inovatif Dalam Kurikulum 2013. Yogyakarta: ArRuzz Media.

Undang-undang Republik Indonesia tentang Sistem Pendidikan Nasional. 2003. Diunduh pada tanggal 7 September 2018, dari http://www.google.com.peraturansistempendidikannasional 